Research Article

\title{
Tensile Properties of Three Selected Collagen Membranes
}

\author{
Perry Raz $\mathbb{D}^{1}$, Tamar Brosh, $^{2}$ Guy Ronen, ${ }^{3}$ and Haim Tal ${ }^{1}$ \\ ${ }^{1}$ Department of Periodontology and Oral Implants, The Goldschleger School of Dental Medicine, Sackler Faculty of Medicine, \\ Tel Aviv University, Tel Aviv, Israel \\ ${ }^{2}$ Department of Oral Biology, The Goldschleger School of Dental Medicine, Sackler Faculty of Medicine, Tel Aviv University, \\ Tel Aviv, Israel \\ ${ }^{3}$ The Goldschleger School of Dental Medicine, Sackler Faculty of Medicine, Tel Aviv University, Tel Aviv, Israel
}

Correspondence should be addressed to Perry Raz; drperioraz@gmail.com

Received 26 August 2019; Accepted 8 October 2019; Published 5 December 2019

Academic Editor: Despina Deligianni

Copyright $\odot 2019$ Perry Raz et al. This is an open access article distributed under the Creative Commons Attribution License, which permits unrestricted use, distribution, and reproduction in any medium, provided the original work is properly cited.

Background. Biological barriers are commonly used to treat alveolar bone defects and guide tissue regeneration. Understanding the biological and mechanical properties of the available membranes is crucial for selecting the one that is optimal for enhancing clinical outcomes. Purpose. To evaluate the mechanical behavior of three different collagen membranes to increasing tensile force in dry and wet conditions. Materials and Methods. Three commercially collagen membranes were selected for analysis: Bio-Gide ${ }^{\circledR}$ (Geistlich Biomaterials, Baden-Baden, Germany), Remaix ${ }^{\mathrm{TM}}$ (RX; Matricel GmbH, Herzogenrath, Germany), and Ossix Plus ${ }^{\circledR}$ (Datum Dental Biotech, Lod, Israel). Increasing tensile forces were applied on 10 dry and wet membranes of standard size via a loading machine. Force and extension values were acquired up to maximum load before failure, and maximum stress, maximum extension, and amount of energy needed for membrane tearing were analyzed. Membranes' densities were also calculated. Results. The Remaix membrane exhibited the highest values of maximum load tensile strength, maximum extension, and maximum energy required for membrane tearing, followed by Bio-Gide. Ossix Plus had the lowest scores in all these parameters. Dry membranes had the highest scores for all parameters except extension. Membrane density was directly and significantly correlated with all tested parameters. Conclusions. The study was undertaken to provide clinicians with data upon which to base the selection of collagen membranes in order to achieve optimal clinical results. It emerged that the mechanical properties of dry and wet collagen membranes were significantly different from one another. Among the 3 tested membranes, Remaix exhibited higher performance results in all the mechanical tests. Collagen membrane density seems to have a significant influence upon mechanical resistance. These findings may also guide manufacturers in improving the quality of their product.

\section{Introduction}

Biological barriers are commonly used to promote guided tissue regeneration (GTR). Regenerative periodontal therapy often aims to restore the periodontal attachment apparatus that had been destroyed due to periodontal disease [1-3]. Treatment of alveolar bone defects (referred to as guided bone regeneration (GBR)) is similarly supported by such barrier membranes [4]. Understanding the biological and mechanical properties of the available membranes is crucial for selecting the one that is optimal for enhancing clinical outcomes. Regardless of whether the procedure is GTR or GBR, the barrier membrane should exhibit all or most of the following qualities:

(a) Biocompatibility that will allow integration of the barrier with the host tissues without eliciting inflammatory responses

(b) A suitable degradation profile to match that of new tissue formation

(c) Appropriate mechanical and physical properties to allow its placement in vivo 
(d) Sufficient sustained strength to avoid membrane collapse and function as a barrier

(e) Cell occlusiveness for the ability to act as a cell barrier, i.e., to exclude undesirable cells from entering the secluded space [5]

Human studies have provided evidence of the effectiveness of regenerative treatment of intrabony defects with collagen membranes, with or without the addition of bone substitutes [6-13]. Combining collagen membrane with bone substitutes may act as a supporting scaffold that prevents the barrier from collapsing, especially in noncontained intrabony defects [10]. Data from systematic reviews have suggested that GTR indeed improves clinical outcomes [11-13]. For the reconstruction of an alveolar bone ridge for implant placement using GBR techniques, the membrane is placed over the defect site, isolating it from the surrounding soft tissues and encouraging population of the site with primarily bone progenitor cells, osteoblasts, and other regenerative factors [14].

Membranes may be classified according to the chemistry of the manufactured material, such as synthetic polymers (epolytetrafluoroethylene (PTFE)), polylactic acid (PLA), polyglycolic acid, synthetic or native collagen, metals (titanium), and inorganic compounds (calcium sulfate). They may also be classified into resorbable and nonresorbable membranes [15]. Collagen membranes are the most popular barriers used in both GTR and GBR procedures, and the collagen for such purposes is available from different animal sources, especially porcine and bovine [13]. The main advantages of resorbable collagen membranes are that collagen is a major constituent of the natural extracellular matrix (ECM) and an important alternative to synthetic polymers due to its excellent cell affinity and biocompatibility [16]. Importantly, the use of nonresorbable membranes increases the risk of membrane exposure to bacterial colonization, thereby possibly inhibiting healing $[17,18]$.

Various cross-linking techniques have been developed to control the absorption time of collagen membranes, including ultraviolet light, hexamethylene di-isocyanate, glutaraldehyde plus irradiation, and diphenylphosphoryl azide [19]. The cross-linking of collagen with aldehyde sugars, especially ribose nonenzymatic glycation, produces collagen barriers that are more resistant to resorption, thus allowing a slower degradation rate [20]. Immobilization of membranes is essential for establishing the proper environment necessary for clot stabilization, cell proliferation and differentiation, and tissue regeneration. Stabilizing of membranes is achieved by sutures and/or miniscrews and pins [21].

It has been claimed that the use of barrier membranes with insufficient stability and inadequate space maintenance in GBR may lead to the displacement of the grafts by the stress generated by the peripheral soft tissues, resulting in the reduction of new bone growth [22]. Therefore, the ideal membrane should be sufficiently rigid to withstand the compression of overlying soft tissues and possess the required degree of plasticity for being easily contoured and molded into the desired shape to conform to the defect. A balance between these mechanical properties is an advantage.
Due to the sparse data available on the mechanical properties of collagen membranes, the aim of this study was to compare the resistance of three commercially available ones to gradually increasing tensile force in dry and wet conditions. The study was undertaken to provide clinicians and manufacturers with data which might improve the clinical selection of a membrane and guide the manufacturing process for yielding better results by providing improved products.

\section{Materials and Methods}

Three commercially available collagen membranes which are used for GBR and/or GTR procedures were selected for the study: two different non-cross-linked collagen membranes, Bio-Gide ${ }^{\circledR}$ (Geistlich Biomaterials, Baden-Baden, Germany) and Remaix ${ }^{\mathrm{TM}}$ (RX; Matricel GmbH, Herzogenrath, Germany), and one cross-linked collagen membrane, Ossix Plus ${ }^{\circledR}$ (Datum Dental Biotech, Lod, Israel).

Bio-Gide is a bilayer barrier made of porcine dermis type I and III collagen with one compact layer facing the soft tissue and acting as a tissue barrier and a second layer that is spongy and porous to allow bone tissue integration [23]. Remaix is composed of a network of highly purified noncross-linked porcine collagen fibers intermingled with porcine elastin fibers. Ossix Plus is a synthetic ribose-induced cross-linked membrane made of porcine tendon type I collagen [24].

The membranes, from Tel Aviv School of Dental Medicine, were cut to pieces of standard size $(5 \times 15 \mathrm{~mm})$ by means of a custom-made guillotine. The mean thickness and volume of each membrane were calculated by measuring the thickness of each membrane at 3 different points by means of an analogue caliper (Kafer F1101/30) with a resolution of $1 \mu \mathrm{m}$ and an error range of $3 \mu \mathrm{m}$ [25]. Specimens were weighed by an analytical balance (Sartorius TE64 Talent Analytical Balance), and their density was calculated by dividing each specimen's weight by its volume. To achieve wet samples, the membranes were soaked in saline solution according to the manufacturer's instructions as follows: Ossix Plus for $3 \mathrm{~min}$, Bio-Gide for $30 \mathrm{~min}$, and Remaix for a few seconds until it was damp. Ten membranes of each group were clamped to a loading machine (Instron, Model 4502, Buckinghamshire, England) equipped with a $100 \mathrm{~N}$ load cell, where the distance between the clamps was maintained at $10 \mathrm{~mm}$. Equal samples of each group $(n=10)$ were tested in dry and wet conditions at a crosshead speed of $1 \mathrm{~mm} / \mathrm{min}$ until the point of membrane tearing. Tensile force (TF) was continuously recorded, and the TF vs. membrane extension result was acquired automatically. Four parameters were considered for mechanical analysis:

(1) Maximal load $(\mathrm{N})$ was measured and recorded at the extreme loading point, just before tearing

(2) Tensile strength (maximum stress, MPa) was calculated as the maximal load divided by the crosssectional area of each specimen

(3) Maximal extension ( $\mathrm{mm}$ ) was measured at the point of maximal load 
(4) The energy applied during loading (J) was calculated as the area under the load extension curve up to maximal load

2.1. Statistical Analysis. The square roots of the parameters were considered for the statistical analysis in order to obtain normal distribution of the results. Comparisons between the parameters were analyzed by analysis of variance with repeated measures with 2 factors: type (manufacturer) and condition (dry or wet) followed by a post hoc test. The $t$-test was applied to verify the differences between tearing forces for the 3 groups. Correlations between the different parameters and the density were tested using the Pearson correlation. Differences were accepted as being significant at a $p$ value $<0.05$ using SPSS ver.20.

\section{Results}

The non-cross-linked membranes, Remaix and Bio-Gide, exhibited nonlinear behavior during loading in dry and wet conditions, whereas the cross-linked membrane, Ossix Plus, exhibited linear behavior only in the dry condition. Therefore, the energy applied during loading was considered rather than the slope of the loading curve of the membranes (representing elastic modulus) (Figure 1).

Both the type of the membrane and their condition (dry or wet) significantly affected the measured parameters in the tensile test $(p<0.001$, two-way ANOVA).

Figure 2 presents the mean maximal load of all 3 membrane groups. The maximal load was significantly higher for membranes in the dry condition compared to the wet condition $(p<0.001)$ : Remaix (dry: $15.67 \pm 5 \mathrm{~N}$, wet: $7.66 \pm 2.65 \mathrm{~N})$ and Bio-Gide (dry: $9.41 \pm 3.16 \mathrm{~N}$, wet: $3.7 \pm 1.43 \mathrm{~N}$ ), with Ossix Plus presenting the lowest maximal force (dry: $7.07 \pm 2.29 \mathrm{~N}$, wet: $1.63 \pm 0.24 \mathrm{~N}$ ).

Figure 3 presents the mean tensile strength of all 3 membrane groups. Remaix scored the highest tensile strength (dry: $10.4 \pm 2.66 \mathrm{MPa}$, wet: $5.25 \pm 1.35 \mathrm{MPa}$ ), followed by Bio-Gide (dry: $4.6 \pm 0.94 \mathrm{MPa}$, wet: $1.68 \pm 0.54 \mathrm{MPa}$ ) and Ossix Plus (dry: $5.13 \pm 2.48 \mathrm{MPa}$, wet: $1.2 \pm 0.14 \mathrm{MPa}$ ); however, Ossix Plus did not show a significant difference compared with Bio-Gide $(p>0.05)$.

The extension of the membranes at maximal load is presented in Figure 4. All the wet membranes extended to a significantly longer distance compared to the dry ones (Tukey's test $p<0.05$ ). Remaix produced the longest extension under both dry and wet conditions (dry: $7.01 \pm 1.38 \mathrm{~mm}$, wet: $12.83 \pm 1.23 \mathrm{~mm}$ ) followed by BioGide (dry: $1.9 \pm 0.15 \mathrm{~mm}$, wet: $2.3 \pm 0.25 \mathrm{~mm}$ ), while Ossix Plus exhibited extension values of $0.06 \pm 0.00 \mathrm{~mm}$ and $1.33 \pm 0.26 \mathrm{~mm}$ in dry and wet conditions, respectively. The membrane type was significantly associated with the maximum extension in both the dry and wet conditions $(p<0.01)$.

Figure 5 depicts the energy required for membrane tensile test. The dry membranes required significantly more energy to tear than the wet ones $(p<0.001)$. The energy needed for tearing the Remaix membrane was the highest (dry: $64.15 \pm 21.77 \mathrm{~J}$, wet: $30.11 \pm 17.01 \mathrm{~J}$ ) followed by BioGide (dry: $4.12 \pm 1.05 \mathrm{~J}$, wet: $2.41 \pm 0.68 \mathrm{~J}$ ) and Ossix Plus (dry: $2.65 \pm 1.51 \mathrm{~J}$, wet: $0.712 \pm 0.11 \mathrm{~J}$ ).

The average physical data of the tested membranes (i.e., thickness and volume) are presented in Table 1. Membrane density was also calculated, and it was found to be similar for both the wet and dry membranes. Membrane thickness was found to be statistically significant between Bio-Gide and Remaix (Bio-Gide was 47\% thicker) and between BioGide and Ossix Plus (Bio-Gide was 58\% thicker). In dry conditions, Remaix was denser than both Bio-Gide and Ossix Plus $\left(0.43 \pm 0.028 \mathrm{mg} / \mathrm{mm}^{3}, 0.33 \pm 0.04 \mathrm{mg} / \mathrm{mm}^{3}\right.$, and $0.22 \pm 0.03 \mathrm{mg} / \mathrm{mm}^{3}$ ), respectively (Table 1 ).

Correlations between the physical parameters and the mechanical data were performed on all the examined membranes, wet or dry $(n=30)$, in order to determine the most important physical character for improving the mechanical performance of membrane. There were significantly high correlations $(p<0.01)$ between the density of the membrane and all measured mechanical parameters in all 3 groups (Table 2).

\section{Discussion}

The primary aim of this study was to determine and analyze the tensile strength of 3 commercially available collagen membranes. Two of them, Remaix and Bio-Gide, are made from native not-cross-linked collagen, while Remaix contains elastin fibers, and the third, Ossix Plus, is made from sugar-induced cross-linked collagen. The results of this analysis revealed clear-cut differences between the examined membranes. The parameters that were measured included maximum load, maximum stress, maximal extension, and energy required for membrane tearing, and Remaix exhibited the highest values for all of them, followed by BioGide and then Ossix Plus. These characteristics applied to both dry and wet membranes. The tensile strengths for all the dry membranes were higher than those of the wet ones, with the exception of the extension parameter. Membrane density correlated positively and significantly with all the other tested parameters. The surface area also correlated positively but not to a level of significance. Membranes' thickness did not have a significance influence on the differences between the examined mechanical properties as indicated by the finding that the Remaix membrane was not the thickest membrane but rather had superior mechanical properties.

While there are no published comparative data on these 3 specific membranes, the current findings are in accordance with Bozkurt et al. [24] who examined the mechanical properties of Bio-Gide and Remaix. Those authors claimed that the tensile stress of the Remaix membrane in dry conditions ("stress at break") was twice that of Bio-Gide. They suggested that the improved mechanical properties of the Remaix membrane may extend the current range of indications for collagen membranes and stressed that high tensile strength and stability of membranes are required for combined horizontal and vertical bone ridge augmentation, where relatively large defects must be bridged and the membrane must be stabilized by being fixed with pins to the 


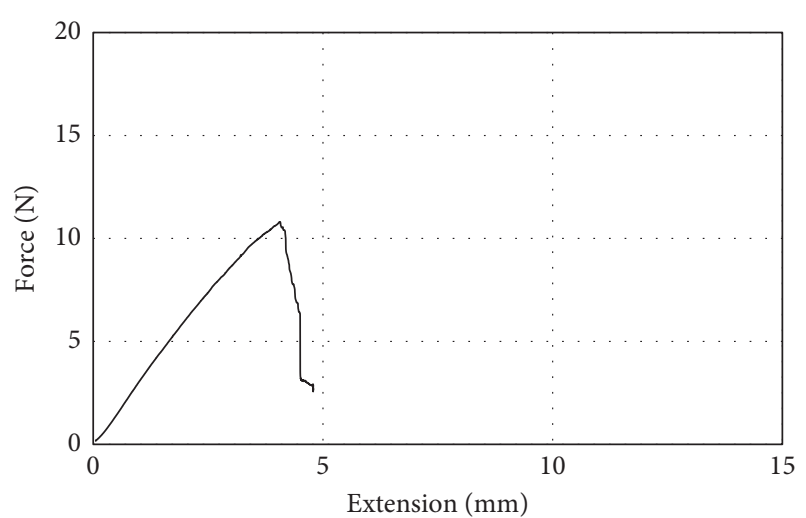

(a)

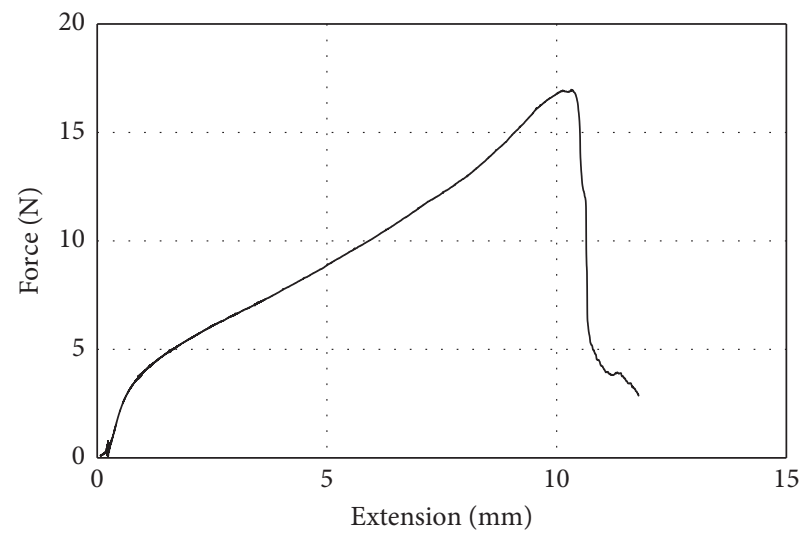

(c)

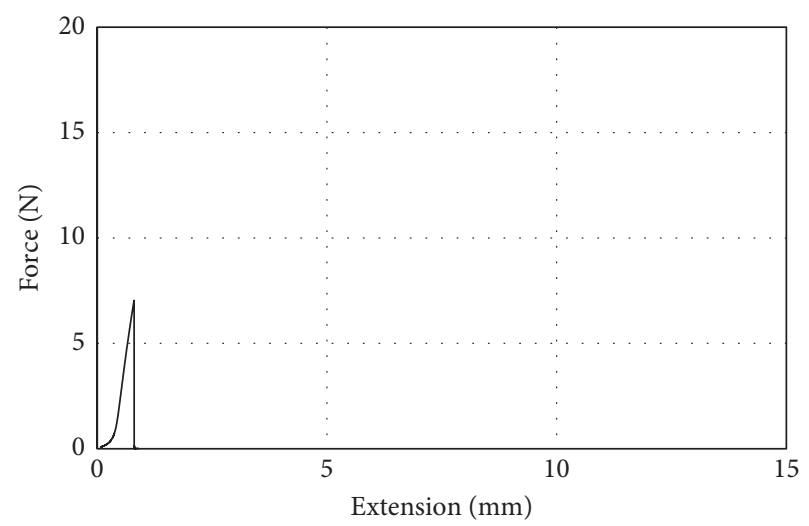

(e)

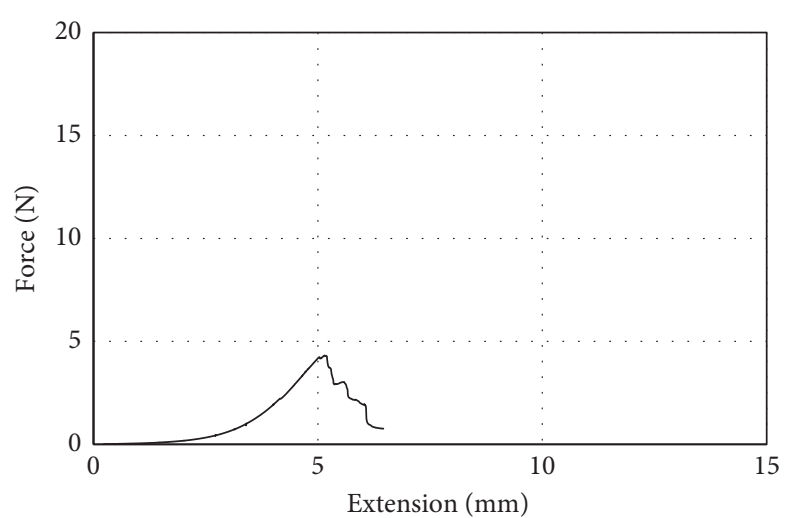

(b)

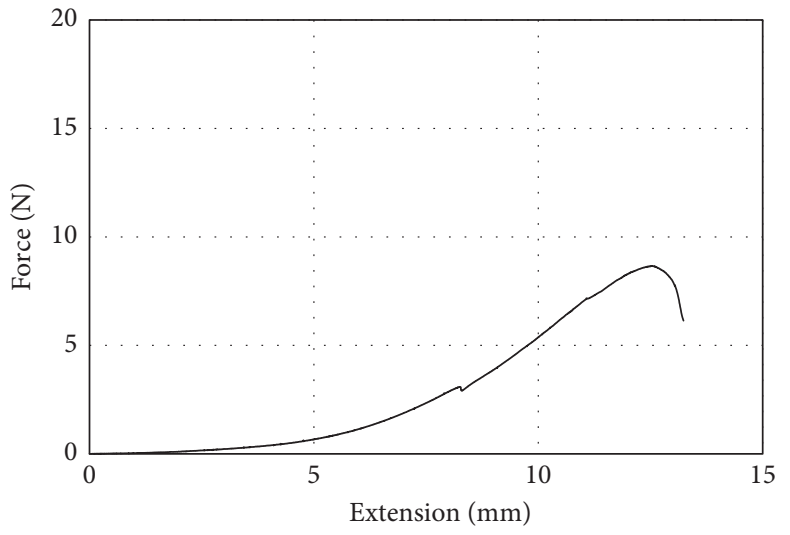

(d)

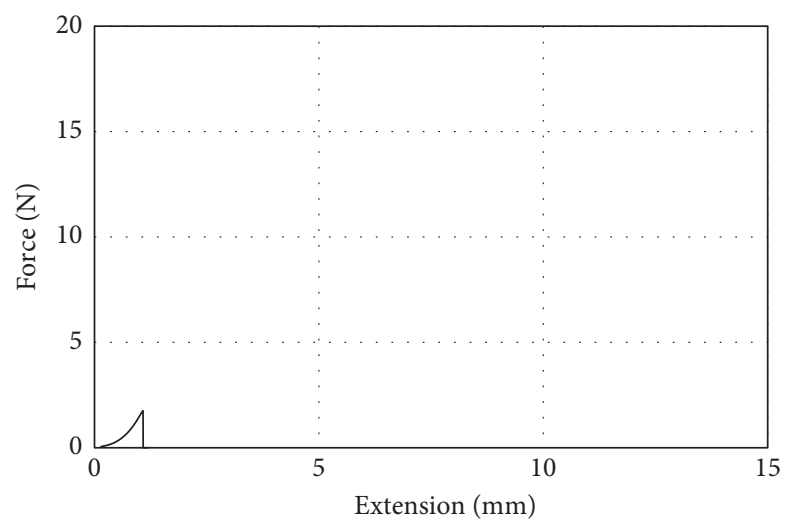

(f)

Figure 1: Characteristic force-extension diagrams: (a) Bio-Gide dry, (b) Bio-Gide wet, (c) Remaix dry, (d) Remaix wet, (e) Ossix Plus dry, and (f) Ossix Plus wet.

surrounding bone. A similar tear load of $1.84 \mathrm{~N}$ was found for Bio-Gide membrane by Ortolani et al. who had applied a mechanical test [25].

The current results are also in accordance with Roeder et al. [26] who investigated the mechanical properties of the collagen type I ECM stress-strain curves of assembled matrices of similar shapes in vitro. They observed that collagen matrices exhibited nonlinear stress-strain curves with 3 distinct regions. The first was a region of small strains called the "toe"" region, which corresponds to the removal of a crimp in the collagen fibrils first at the fibrillar level and then at the molecular level. The second was a "linear" region, representing the stiffness of the collagen fibrils which increases considerably with extension. This region has been associated with stretching of the collagen triple helices or of the cross-links between the helices, implying a side-by-side gliding of neighboring molecules. The third was the "failure" region, representing disruption of the fibril structure. Additionally, the stress-strain response of the collagen matrices was shown to be sensitive to strain rate, a characteristic of 


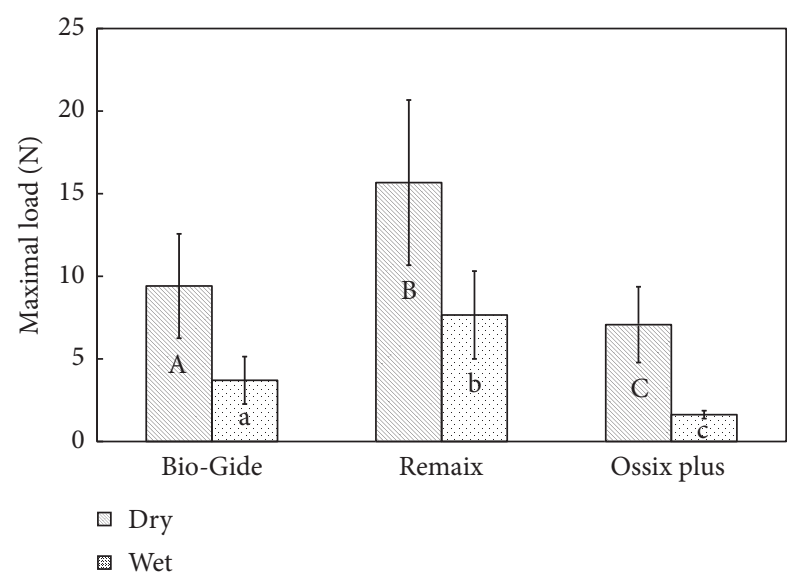

Figure 2: Comparison between the maximum loads that were needed for reaching the tearing/failure point of the membranes in dry and wet conditions $(N=10)$. Groups with different letters, upper case and lower case, per material and between materials are significantly different $(p<0.05)$.

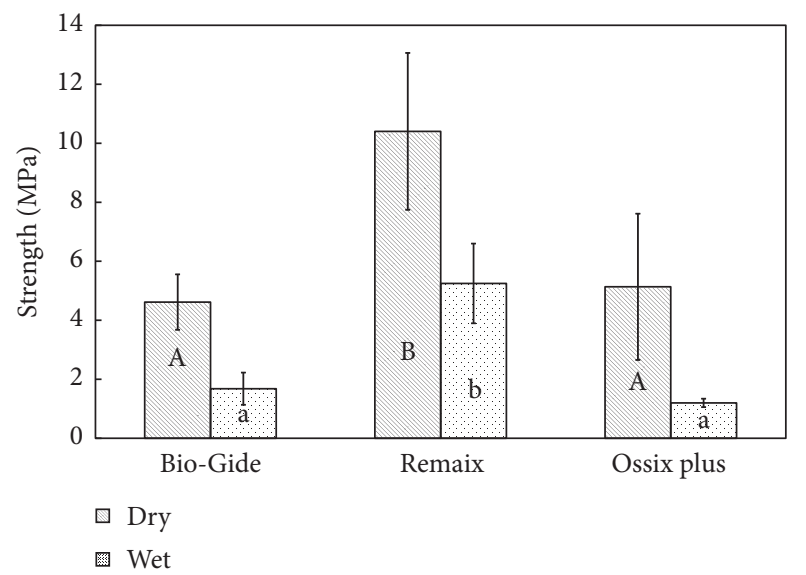

FIgURE 3: Comparison of maximum stress (maximum load to the cross section area, $\mathrm{MPa}$ ) measured between the membranes and in dry and wet conditions $(N=10)$. Groups with different letters, upper case and lower case, per material and between materials are significantly different $(p<0.05)$.

viscoelastic materials. Finally, the mechanical nature of collagen matrices was shown to be consistent with the properties of their fibrils, which is their main structural component.

The differences between the 3 collagen membranes that emerged from the results of this study may be explained by the different structure of a given membrane's material. The "Glymatrix" technology used for producing the ribose-induced cross-linking of the Ossix Plus membrane was probably responsible for the increased fragility and brittleness of the synthetic membrane, whereas the native, noncrossed-linked collagen of Bio-Gide and Remaix had more elasticity, a feature that would improve the ability of handling as well as the adaptation to more irregular surfaces. In addition, Bio-Gide has individual collagen fibrils interlaced to form coarse collagen strands [27].

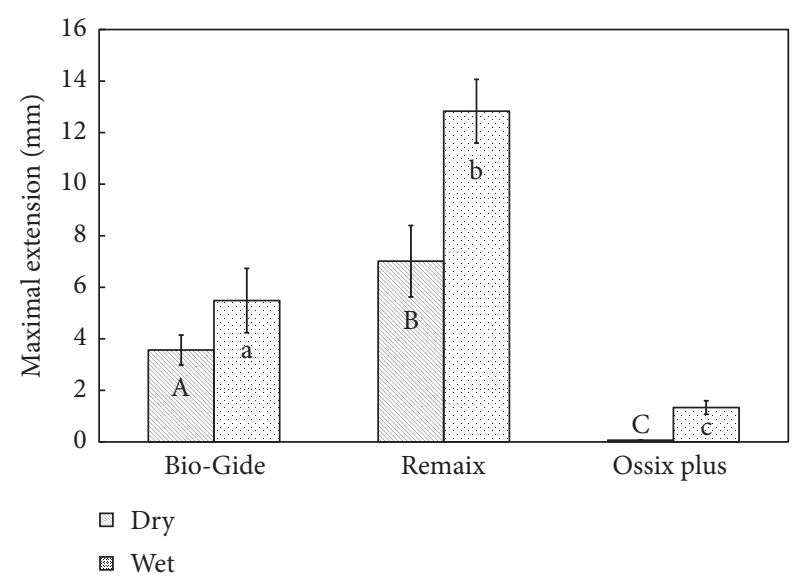

Figure 4: Comparison between the maximum extensions of the membranes at the tearing/failure point and between dry and wet conditions $(N=10)$. Groups with different letters, upper case and lower case, per material and between materials are significantly different $(p<0.05)$.

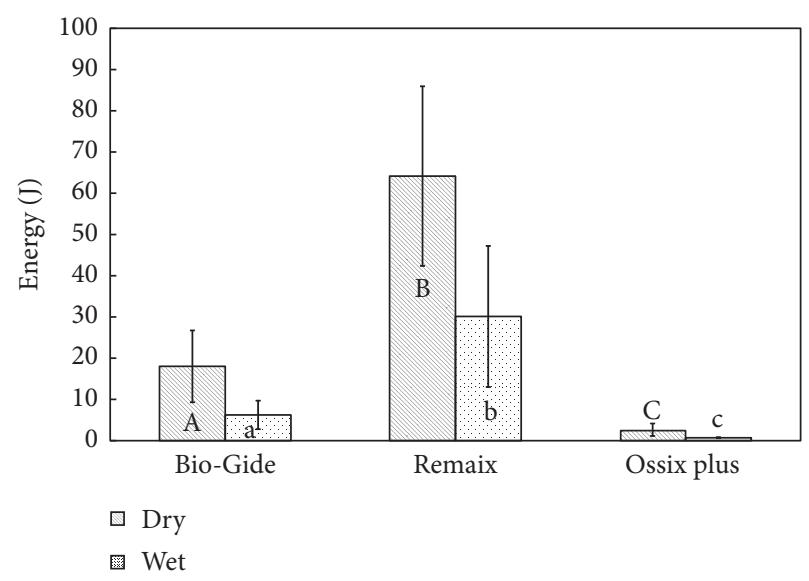

FIgURE 5: Comparison between the energy required for membrane tearing/failure which was calculated as the area under the curve (AUC). The energy $(\mathrm{J})$ required for tearing membranes in dry and wet conditions $(N=10)$. Groups with different letters, upper case and lower case, per material and between materials are significantly different $(p<0.05)$.

According to the manufacturer's instructions for use, the membranes should be placed in saline before placement in situ. However, Coïc et al. [28], found that extensive moistening considerably alters the mechanical properties of the membranes, an observation that is in accordance with the present results. In contrast, this does not happen to the Ossix Plus crossed-linked membrane, which has a fragile response to the application of tensile forces in either the dry or wet condition.

Depalle et al. [29] claimed that the mechanical response of cross-linked fibrils exhibits a 3-phase pattern of behavior: (i) an initial elastic deformation corresponding to the uncoiling of the collagen molecule, (ii) a linear regime dominated by molecules gliding, and (iii) a second stiffer elastic regime related to the stretching of the backbone of the 
TABLe 1: Mean values of physical data of the tested membranes.

\begin{tabular}{lcccccc}
\hline Mean \pm SD & Bio-Gide dry & Bio-Gide wet & Remaix dry & Remaix wet & Ossix Plus dry & Ossix Plus wet \\
\hline Thickness $(\mathrm{mm})$ & $0.4 \pm 0.11 \mathrm{a}$ & $0.44 \pm 0.11 \mathrm{a}$ & $0.29 \pm 0.03 \mathrm{~b}$ & $0.28 \pm 0.04 \mathrm{~b}$ & $0.26 \pm 0.03 \mathrm{c}$ & $0.27 \pm 0.02 \mathrm{c}$ \\
Volume $\left(\mathrm{mm}^{3}\right)$ & $30.50 \pm 7.98 \mathrm{a}$ & $33.17 \pm 8.5 \mathrm{a}$ & $22.24 \pm 2.22 \mathrm{~b}$ & $21.54 \pm 2.71 \mathrm{~b}$ & $18.84 \pm 2.22 \mathrm{c}$ & $19.92 \pm 2.08 \mathrm{c}$ \\
Density $\left(\mathrm{mg} / \mathrm{mm}^{3}\right)$ & $0.33 \pm 0.03 \mathrm{a}$ & $0.3 \pm 0.03 \mathrm{a}$ & $0.43 \pm 0.028 \mathrm{~b}$ & $0.4 \pm 0.03 \mathrm{~b}$ & $0.22 \pm 0.03 \mathrm{c}$ & $0.23 \pm 0.02 \mathrm{c}$ \\
\hline
\end{tabular}

Groups with different letters per material and between materials are significantly different $(p<0.05)$.

TABLE 2: Correlations between the membranes' physical parameters and the measured mechanical results.

\begin{tabular}{|c|c|c|c|c|c|c|c|c|}
\hline \multirow{2}{*}{ Mechanical results/physical parameters } & \multicolumn{2}{|c|}{ Max. load (N) } & \multicolumn{2}{|c|}{ Max. extension (mm) } & \multicolumn{2}{|c|}{ Energy (J) } & \multicolumn{2}{|c|}{ Max. stress $(\mathrm{MPa})$} \\
\hline & Dry & Wet & Dry & Wet & Dry & Wet & Dry & Wet \\
\hline Surface area $\left(\mathrm{mm}^{2}\right)$ & 0.26 & $0.46^{* *}$ & $0.42^{*}$ & $0.51^{* *}$ & 0.33 & $0.42^{*}$ & 0.10 & 0.35 \\
\hline Average thickness (mm) & 0.30 & 0.16 & 0.35 & 0.02 & 0.25 & 0.02 & -0.11 & -0.19 \\
\hline Volume $\left(\mathrm{mm}^{3}\right)$ & 0.31 & 0.19 & $0.37^{*}$ & 0.06 & 0.27 & 0.05 & -0.10 & -0.16 \\
\hline Density $\left(\mathrm{mg} / \mathrm{mm}^{3}\right)$ & $0.78^{* *}$ & $0.85^{* *}$ & $0.91^{* *}$ & $0.90^{* *}$ & $0.92^{* *}$ & $0.84^{* *}$ & $0.68^{* *}$ & $0.90^{* *}$ \\
\hline Cross-sectional area $\left(\mathrm{mm}^{2}\right)$ & $0.68^{* *}$ & 0.17 & $0.36^{*}$ & 0.04 & 0.26 & 0.03 & -0.11 & -0.18 \\
\hline
\end{tabular}

$N=30$, all examined type of membranes, wet or dry. ${ }^{*} p<0.05,{ }^{* *} p<0.01$.

tropocollagen molecules until the fibril ruptures. Those authors suggest that both the density and the type of crosslinks dictate the stiffness of a large deformation regime by increasing the number of interconnected molecules, while the mechanical properties of the cross-links determine the failure strain and strength of the fibril. These findings reveal that cross-links may play an essential role in creating an interconnected fibrillar material of tunable toughness and strength [29].

The membranes selected for this study included native and synthetic collagens. The microstructure of these was unequivocally different, making it impossible to evaluate the influence of the collagen fibers' orientation on the results $[15,26]$.

Thompson and Czernuszka examined the effect of crosslinking of collagen on the mechanical properties of the polymer using 2 techniques: induction by glutaraldehyde and application of a combination of dehydrothermal treatment and cyanamide. These authors examined the materials, before and after cross-linking. Their results showed that cross-linking itself increased the elastic modulus, reduced the strain to failure, and had little effect on the fracture stress (ultimate tensile strength) of collagen under the experimental conditions [30].

In search for an ideal GTR/GBR membrane, the characteristics of the mechanical and physical properties must be considered in order to avoid membrane collapse and to improve the ease of handling and placement. Recent advances in the development of GTR/GBR membranes with the desirable features and properties have been made by combining natural and synthetic polymers with or without therapeutic drugs or biologic mediators [31]. The rationale of having a regenerative membrane with a graded structure is based on the principle that one can tailor the properties of the different layers to design a membrane that will retain its structural, dimensional, and mechanical integrity long enough to enhance periodontal regeneration. However, most of these methods result in membranes with reduced efficacy for clinical application due to high density and difficulty in handling as well as a heterogeneous, nonuniform degradation rate [32].

Further investigation of the correlation between membrane structure and density, as well as of the biological, clinical, and functional qualities of membranes in current use, is recommended.

\section{Conclusions}

This research presents data on the mechanical qualities of clinically used collagen membranes.

Collagen membrane density has a significant positive influence upon resistance to tearing. Dry membranes exhibited significantly higher mechanical resistance to tensile forces than wet ones. Among the 3 membranes examined, Remaix ${ }^{\mathrm{TM}}$ was significantly more resistant to tensile force than Bio-Gide ${ }^{\circledR}$ and Ossix Plus ${ }^{\circledR}$, while Ossix Plus ${ }^{\circledR}$ was significantly more fragile than Remaix $^{\mathrm{TM}}$ and Bio-Gide ${ }^{\circledR}$.

\section{Abbreviations}

BTB: Biological tissue barriers

GTR: Guided tissue regeneration

GBR: Guided bone regeneration

PTFE: Polytetrafluoroethylene

ECM: Extracellular matrix

TF: Tensile force

FGM: Functionally graded membrane

PLCL: Poly (d,l-lactide-co-caprolactone).

\section{Data Availability}

The raw data used to support the findings of this study are included within the supplementary information.

\section{Conflicts of Interest}

The authors declare no conflicts of interest related to this study. 


\section{Authors' Contributions}

Perry Raz, Tamar Brosh and Haim Tal contributed equally to this study.

\section{Acknowledgments}

This study was supported in part by a grant from the internal fund of the Maurice and Gabriela Goldschleger School of Dental Medicine and the Gerald Niznick Chair of implant research at Tel Aviv University.

\section{Supplementary Materials}

The data include the physical measurements (e.g., weight, length, and density) of each sample of the examined membrane and the mechanical measurements of the tensile test. The averages were included too. B, Biogide; O, Ossix-plus; R, Remaix, wet/dry (no tags). (Supplementary Materials)

\section{References}

[1] G. Polimeni, A. V. Xiropaidis, and U. M. Wikesjö, "Biology and principles of periodontal wound healing/regeneration," Periodontology 2000, vol. 41, no. 1, pp. 30-47, 2006.

[2] G. Greenstein and J. G. Caton, "Biodegradable barriers and guided tissue regeneration," Periodontology 2000, vol. 1, no. 1, pp. 36-45, 1993.

[3] S. Nyman, J. Gottlow, T. Karring, and J. Lindhe, "The regenerative potential of the periodontal ligament. An experimental study in the monkey," Journal of Clinical Periodontology, vol. 9, no. 3, pp. 257-265, 1982.

[4] B. Wessing, S. Lettner, and W. Zechner, "Guided bone regeneration with collagen membranes and particulate graft materials: a systematic review and meta-analysis," The International Journal of Oral \& Maxillofacial Implants, vol. 33, no. 1, pp. 87-100, 2018.

[5] Y. D. Rakhmatia, Y. Ayukawa, A. Furuhashi, and K. Koyano, "Current barrier membranes: titanium mesh and other membranes for guided bone regeneration in dental applications," Journal of Prosthodontic Research, vol. 57, no. 1, pp. 3-14, 2013.

[6] R. Parodi, G. Carusi, G. Santarelli, F. Nanni, R. Pingitore, and G. Brunel, "Guided tissue regeneration employing a collagen membrane in a human periodontal bone defect: a histologic evaluation," The International Journal of Periodontics \& Restorative Dentistry, vol. 17, no. 3, pp. 282-291, 1997.

[7] M. Camelo, M. L. Nevins, R. K Schenk et al., "Clinical, radiographic, and histologic evaluation of human periodontal defects treated with Bio-Oss and Bio-Gide," The International Journal of Periodontics \& Restorative Dentistry, vol. 18, no. 4, pp. 321-331, 1998.

[8] P. Cortellini, G. P. Prato, and M. S. Tonetti, "Periodontal regeneration of human infrabony defects I. Clinical measures," Journal of Periodontology, vol. 64, no. 4, pp. 254-260, 1993.

[9] M. A. Brunsvold and J. T. Mellonig, "Bone grafts and periodontal regeneration," Periodontology 2000, vol. 1, no. 1, pp. 80-91, 1993.

[10] A. Sculean, A. Stavropoulos, P. Windisch, T. Keglevich, T. Karring, and I. Gera, "Healing of human intrabony defects following regenerative periodontal therapy with a bovine- derived xenograft and guided tissue regeneration," Clinical Oral Investigations, vol. 8, no. 2, pp. 70-74, 2004.

[11] L. Trombelli, L. J. A. Heitz-Mayfield, I. Needleman, D. Moles, and A. Scabbia, "A systematic review of graft materials and biological agents for periodontal intraosseous defects," Journal of Clinical Periodontology, vol. 29, no. s3, pp. 117-135, 2002.

[12] M. A. Reynolds, M. E. Aichelmann-Reidy, G. L. Branch-Mays, and J. C. Gunsolley, "The efficacy of bone replacement grafts in the treatment of periodontal osseous defects. A systematic review," Annals of Periodontology, vol. 8, no. 1, pp. 227-265, 2003.

[13] C. Stoecklin-Wasmer, A. W. S. Rutjes, B. R. Da Costa, G. E. Salvi, P. Jüni, and A. Sculean, "Absorbable collagen membranes for periodontal regeneration: a systematic review," Journal of Dental Research, vol. 92, no. 9, pp. 773-781, 2013.

[14] I. Elgali, A. Turri, W. Xia et al., "Guided bone regeneration using resorbable membrane and different bone substitutes: early histological and molecular events," Acta Biomaterialia, vol. 29, pp. 409-423, 2016.

[15] M. C. Bottino, V. Thomas, G. Schmidt et al., "Recent advances in the development of GTR/GBR membranes for periodontal regeneration-a materials perspective," Dental Materials, vol. 28, no. 7, pp. 703-721, 2012.

[16] J. Behring, R. Junker, X. F. Walboomers, B. Chessnut, and J. A. Jansen, "Toward guided tissue and bone regeneration: morphology, attachment, proliferation, and migration of cells cultured on collagen barrier membranes. A systematic review," Odontology, vol. 96, no. 1, pp. 1-11, 2008.

[17] S. A. Jovanovic and M. Nevins, "Bone formation utilizing titanium-reinforced barrier membranes," The International Journal of Periodontics \& Restorative Dentistry, vol. 15, no. 1, pp. 56-69, 1995.

[18] H. Nowzari, F. Matian, and J. Slots, "Periodontal pathogens on polytetrafluoroethylene membrane for guided tissue regeneration inhibit healing," Journal of Clinical Periodontology, vol. 22, no. 6, pp. 469-474, 1995.

[19] S. Tanaka, G. Avigad, E. F. Eikenberry, and B. Brodsky, "Isolation and partial characterization of collagen chains dimerized by sugar-derived cross-links," The Journal of Biological Chemistry, vol. 263, no. 33, pp. 17650-17657, 1988.

[20] P. Bunyaratavej and H.-L. Wang, "Collagen membranes: a review," Journal of Periodontology, vol. 72, no. 2, pp. 215-229, 2001.

[21] K. Stetzer, G. Cooper, R. Gassner, R. Kapucu, R. Mundell, and M. P. Mooney, "Effects of fixation type and guided tissue regeneration on maxillary osteotomy healing in rabbits," Journal of Oral and Maxillofacial Surgery, vol. 60, no. 4, pp. 427-436, 2002.

[22] D. Buser, K. Dula, H. P. Hirt, and R. K. Schenk, "Lateral ridge augmentation using autografts and barrier membranes: a clinical study with 40 partially edentulous patients," Journal of Oral and Maxillofacial Surgery, vol. 54, no. 4, pp. 420-432, 1996.

[23] Z. Sheikh, J. Qureshi, A. M. Alshahrani et al., "Collagen based barrier membranes for periodontal guided bone regeneration applications," Odontology, vol. 105, no. 1, pp. 1-12, 2017.

[24] A. Bozkurt, C. Apel, B. Sellhaus et al., "Differences in degradation behavior of two non-cross-linked collagen barrier membranes: an in vitro and in vivo study," Clinical Oral Implants Research, vol. 25, no. 12, pp. 1403-1411, 2014.

[25] E. Ortolani, F. Quadrini, D. Bellisario, L. Santo, A. Polimeni, and A. Santarsiero, "Mechanical qualification of collagen 
membranes used in dentistry," Annali Dell'Istituto Superiore di Sanità, vol. 51, no. 3, pp. 229-235, 2015.

[26] B. A. Roeder, K. Kokini, J. E. Sturgis, J. P. Robinson, and S. L. Voytik-Harbin, "Tensile mechanical properties of threedimensional type I collagen extracellular matrices with varied microstructure," Journal of Biomechanical Engineering, vol. 124, no. 2, pp. 214-222, 2002.

[27] H. Tal, O. Moses, A. Kozlovsky, and C. Nemcovsky, Bioresorbable Collagen Membranes for Guided Bone Regeneration, InTechOpen, London, UK, 2012, http://www. intechopen.com/embed/bone-regeneration/bioresorbablecollagen-membranes-for-guided-bone-regeneration.

[28] M. Coïc, V. Placet, E. Jacquet, and C. Meyer, "Mechanical properties of collagen membranes used in guided bone regeneration: a comparative study of three models," Revue de Stomatologie et de Chirurgie Maxillo-Faciale, vol. 111, no. 5-6, pp. 286-290, 2010.

[29] B. Depalle, Z. Qin, S. J. Shefelbine, and M. J. Buehler, "Influence of cross-link structure, density and mechanical properties in the mesoscale deformation mechanisms of collagen fibrils," Journal of the Mechanical Behavior of Biomedical Materials, vol. 52, pp. 1-13, 2015.

[30] J. I. Thompson and J. T. Czernuszka, "The effect of two types of cross-linking on some mechanical properties of collagen," Bio-Medical Materials and Engineering, vol. 5, no. 1, pp. 3748, 1995.

[31] M. C. Bottino and V. Thomas, "Membranes for periodontal regeneration-a materials perspective," Frontiers of Oral Biology, vol. 17, pp. 90-100, 2015.

[32] I. Elgali, O. Omar, C. Dahlin, and P. Thomsen, "Guided bone regeneration: materials and biological mechanisms revisited," European Journal of Oral Sciences, vol. 125, no. 5, pp. 315-337, 2017. 


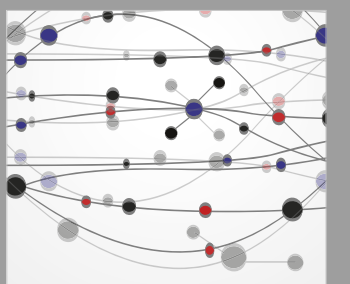

The Scientific World Journal
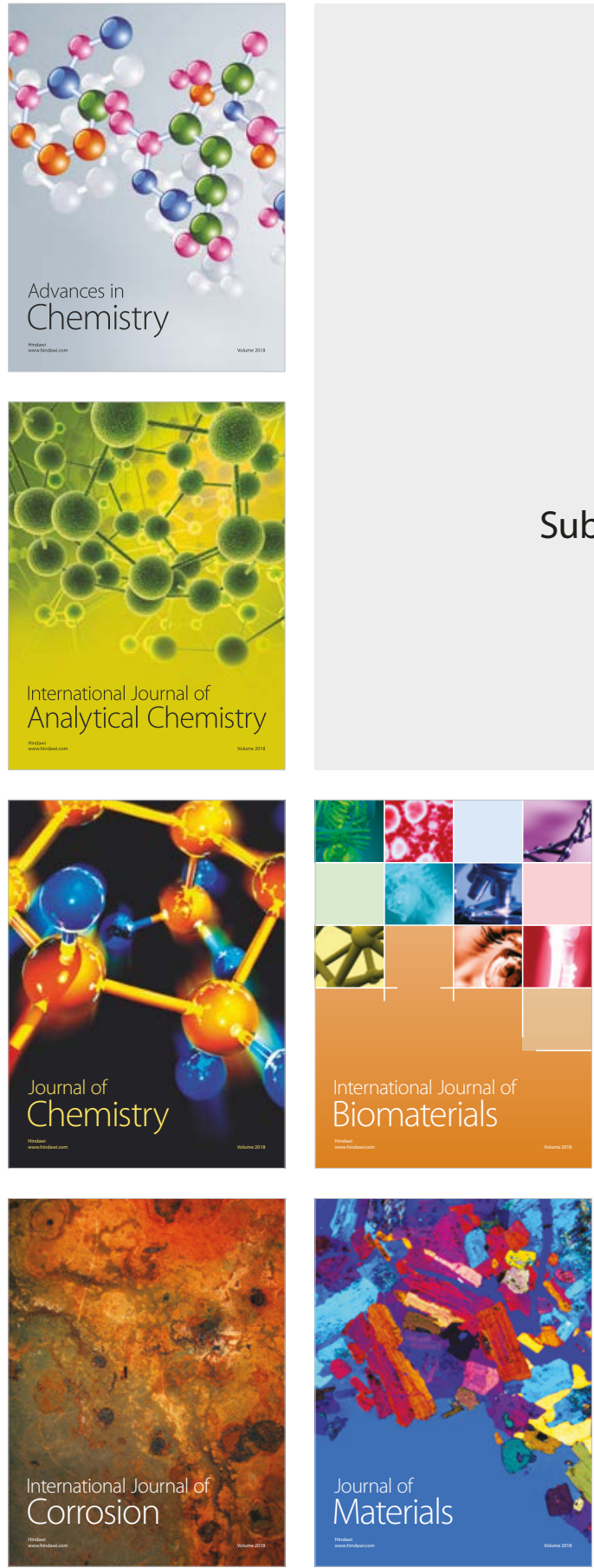

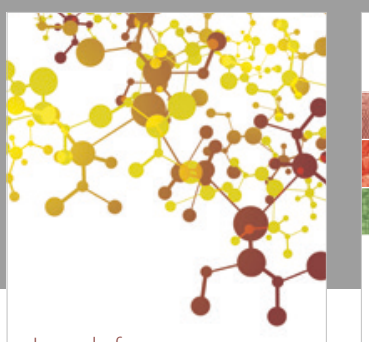

Journal of

Applied Chemistry
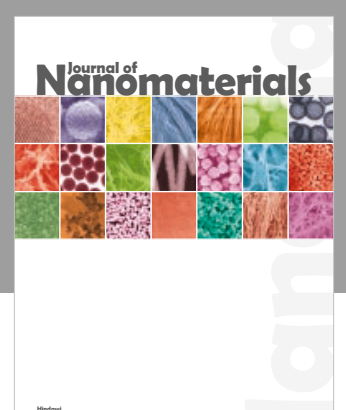

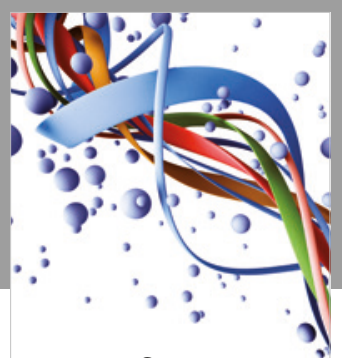

Scientifica

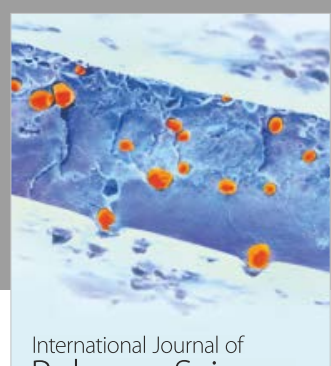

Polymer Science

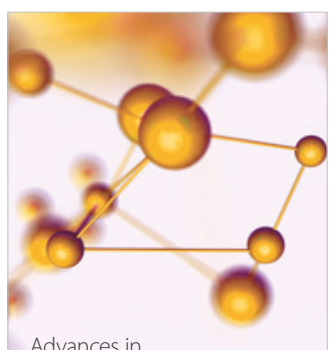

Physical Chemistry
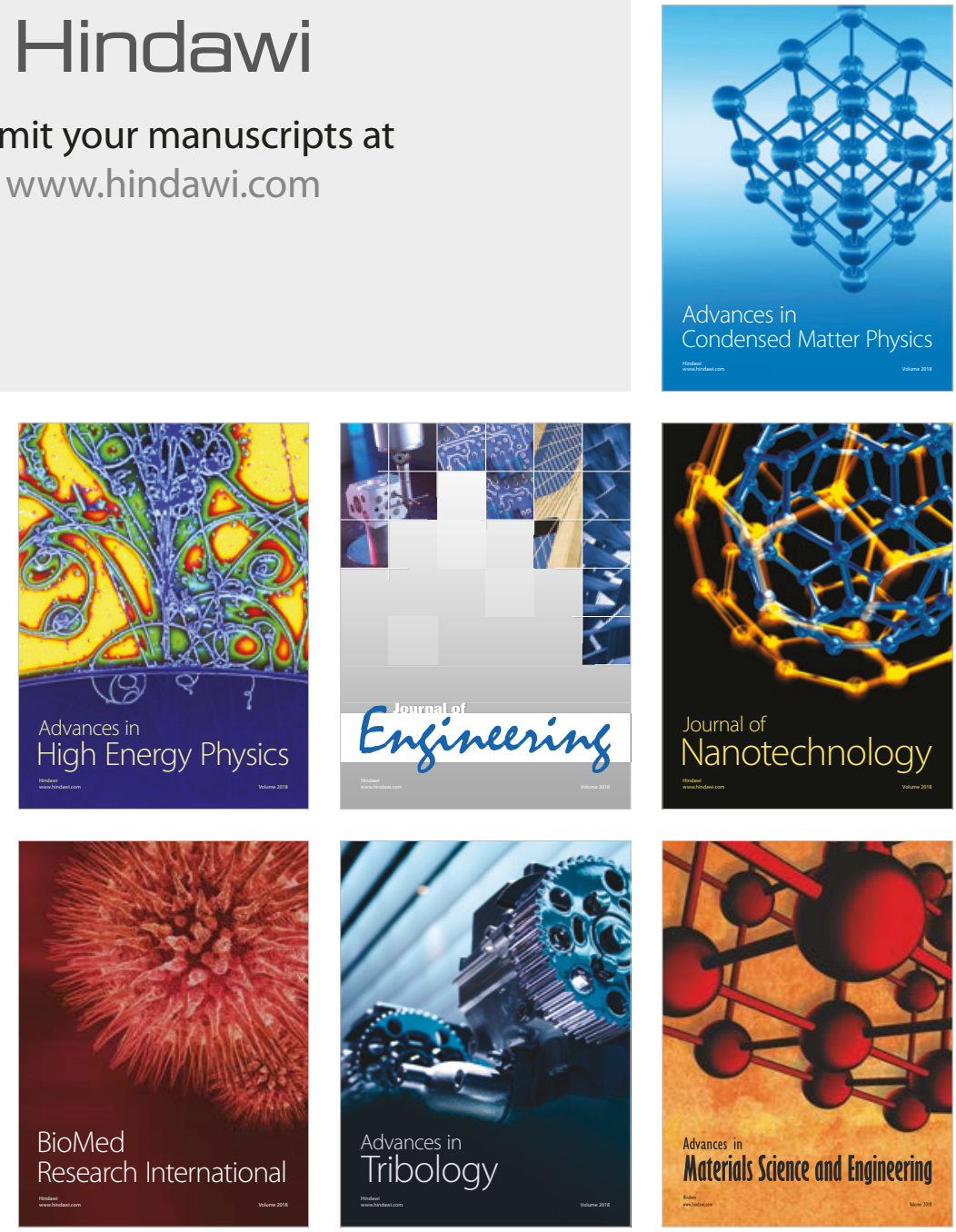